\title{
Mathematical Derivation of Switching Angles of Multilevel Voltage Source Inverter based on Alternative Phase Opposition Disposition (APOD)
}

\author{
Mohd Alif Ismail ${ }^{1, *}$, Mohd Junaidi Abdul Aziz ${ }^{2}$, Muhd Hafizi Idris ${ }^{1}$, Noor Fazliana \\ Fadzail $^{1}$, Mohd Saufi Ahmad ${ }^{1}$, Melaty Amirruddin ${ }^{1}$, Farrah Salwani Abdullah ${ }^{1}$, and \\ Nurhakimah Mohd Mukhtar ${ }^{1}$ \\ ${ }^{1}$ PPK Sistem Elektrik, Universiti Malaysia Perlis \\ ${ }^{2}$ Faculty of Electrical Engineering, Universiti Teknologi Malaysia
}

\begin{abstract}
Modular structured multilevel inverter is very useful for electrical application especially in high voltage and high power applications. The main function of this multilevel inverter is to produce multilevel AC output voltage from several separate DC sources. This project is to derive a newmathematical formulation of multilevel voltage source inverter switching instants. The proposed method for this project is based on the sinusoidal natural sampling PWM (SPWM) by comparing several modified modulation signal with a triangular carrier signal. This resulting intersection points between this modulation and carrier signal become the switching instants of the PWM pulses. Derivation also based on Alternative Phase opposition disposition (APOD). A cascaded multilevel inverter is selected as a topology for this project due to major advantages compare with other topology. The derived formula is analyzed by using MATLAB simulation software. It is found that the results that use the derived formula are almost identical to simulation result.
\end{abstract}

\section{Introduction}

The Multilevel Voltage Source Inverter (MVSI) has drawn tremendous interest in the power industry. Multilevel inverter is an array of capacitors voltage sources and power semiconductor switches which will generate an output voltage of stepped waveform [1]. This inverter is commonly use in application of high voltage and high power. It also has a few advantages. It is easier to build a high voltage and high power inverter with the multilevel structure. This is due to the way in which devices voltage stresses are controlled in the structure. The power rating can be increase by increasing the number of voltage levels in the inverter without requiring higher ratings on individual devices.

Besides that, the multilevel voltage source inverter also has other advantages such as

\footnotetext{
${ }^{*}$ Corresponding author: alifismail@unimap.edu.my
} 
possibility to construct more cheap applications that does not need galvanic isolation such as adjustable speed drives. Furthermore, multilevel voltage source inverter also can improve harmonics performance where it can reduce switching losses. This is very important during application of high power as increased power losses can complicate thermal management system design. One of the famous techniques that normally be applied to the multilevel inverter is sinusoidal pulse width modulation (SPWM) [4].

\section{Methodology}

This project is focused on sinusoidal natural sampling PWM (SPWM) since SPWM is the most popular modulation method. The SPWM for multilevel voltage source inverter is based on the intersection between triangular carrier signals with a modified sinusoidal signal. The switching angle of the PWM pulses is come from the points of intersection. As far as the carrier signals alignment is concerned, three carrier disposition method are suggested which are Alternative Phase Opposition Disposition (APOD), Phase Opposition Disposition (POD) and Phase Disposition (PD) [3].

For this project, it only focuses on derivation of the switching angle equations for APOD Scheme. The topology that had been selected for this project is Cascaded Multilevel Inverters (CMI) because CMI have several advantages compare to other topologies [3].

\subsection{Mathematical derivation of the switching angles equations for Alternative Phase Opposition Disposition (APOD) scheme.}

The switching angle point is presented by $\alpha$ and this point is obtained from intersection between carrier signal and modulation signal. To illustrate the principle of the proposed scheme, a five level inverter had being used in this project. Figure 1 shows the output of PWM pulses generate from intersection between modulation signal and carrier signal for APOD scheme. For this five level output, the switching point are obtain from intersection between four modulation signals that is $\mathrm{S}_{1}(\mathrm{k})$ and $\mathrm{S}_{2}(\mathrm{k})(0<\mathrm{t}<\pi), \mathrm{S}_{3}(\mathrm{k})$ and $\mathrm{S}_{4}(\mathrm{k})(\pi<\mathrm{t}<$ $2 \pi)$ with single triangular carrier $\mathrm{c}(\mathrm{k})$. Signal $\mathrm{S}_{2}(\mathrm{k})$ is actually similar with $\mathrm{S}_{1}(\mathrm{k})$ and only shifted down by the amplitude of triangular carrier signal Ac.

The PWM pulses for level 1 output signal is obtain from the comparison between modified sinusoidal signal, $\mathrm{S}_{1}(\mathrm{k})$ and carrier signal, $\mathrm{c}(\mathrm{k})$, while for level 2 output signal is obtain from comparison between modified sinusoidal signal, $\mathrm{S}_{2}(\mathrm{k})$ and carrier signal, $\mathrm{c}(\mathrm{k})$. The comparison is designed such that if modified sinusoidal signal, $\mathrm{S}_{1}(\mathrm{k})$ is greater than carrier signal, $\mathrm{c}(\mathrm{k})$, a pulse-width for level 1 is generated and if the modified sinusoidal signal, $\mathrm{S}_{2}(\mathrm{k})$ is greater than carrier signal, $\mathrm{c}(\mathrm{k})$, a pulse-width for level 2 is generated. So, if there is no intersection, then output signal remain at 0 . As a result, a multilevel output voltage Vout is produce. Figure 2 show that the $k_{t h}$ rising edge is defined as the intersection of the negative slope carrier, $c^{-}(k)$, positive slope carrier $c^{+}(k)$ and two set of modulating signals $\mathrm{S}_{1}(\mathrm{k})$ and $\mathrm{S}_{2}(\mathrm{k})$. 


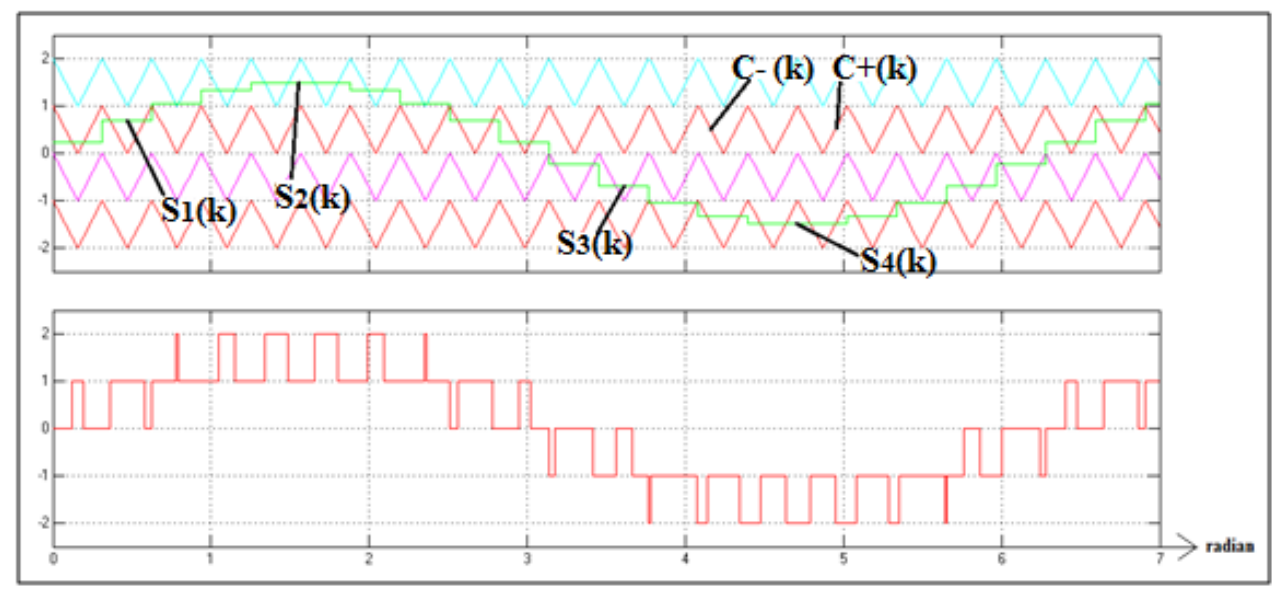

Fig. 1. The PWM pulse generate from intersection between modulation Signal and carrier signal for Alternative Phase Opposition Dispossion (APOD) scheme.

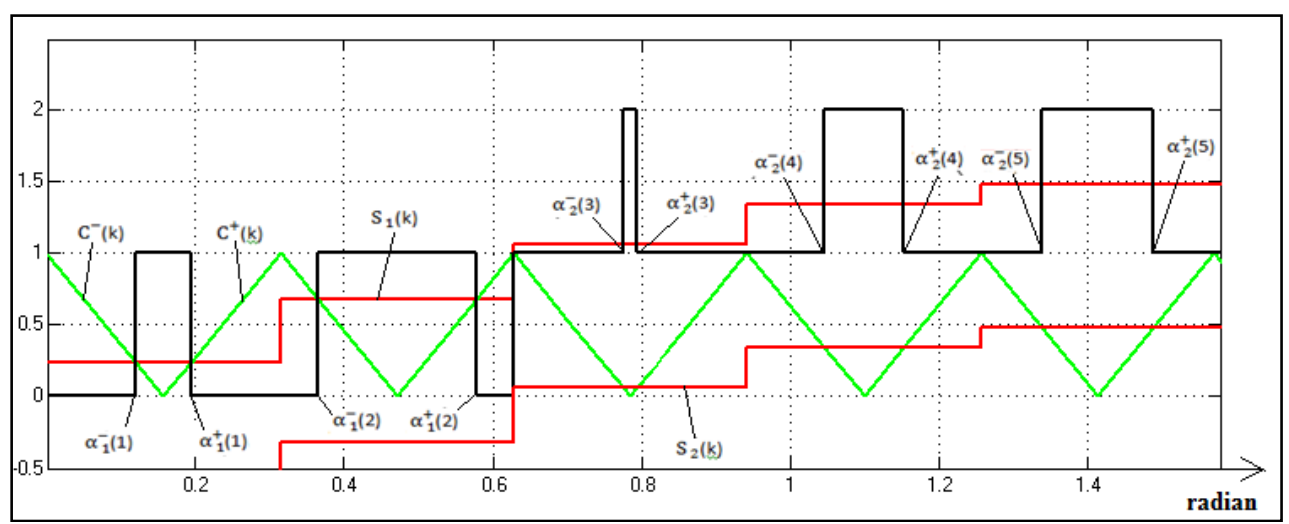

Fig. 2. Intersection between modified sinusoidal modulation signals and single carrier signal with it symbol.

\subsubsection{First step : Find the carrier signal equation, $c(k)$.}

To find equation for $C_{l}^{-}$(negative slope at level 1), basic equation need to be use that is $\mathrm{y}=$ $\mathrm{mx}+\mathrm{c}$ where $\mathrm{y}=C_{l}^{-}$and $\mathrm{x}=\alpha$.

For $C_{l}^{-}(1)$,

$m=\frac{-A_{C}}{\frac{T_{C}}{2}}, \quad c=A_{C}, \quad$ So, equation for the $C_{1}^{-}(1)$ is $\quad C_{1}^{-}(1)=\frac{-A_{C}}{\left(\frac{T_{C}}{2}\right)} \propto+A_{C}$

For $C_{l}^{-}(2)$,

$m=\frac{-A_{C}}{\frac{T_{C}}{2}}, \quad c=3 A_{C}, \quad$ So, equation for the $C_{l}^{-}(2)$ is $\quad C_{1}^{-}(2)=\frac{-A_{C}}{\left(\frac{T_{C}}{2}\right)} \propto+3 A_{C}$

General equation for $C_{1}^{-}$is

$C_{1}^{-}(k)=\frac{-A_{C}}{\left(\frac{T_{C}}{2}\right)} \propto_{1}^{-}+(2 k-1) A_{C}$ Where $\mathrm{k}=1,2,3,4 .$. 
By using similar method as above, the equation for ${C_{l}}^{+}$(positive slope) can be obtain.

General equation for $C_{l}{ }^{+}$is

$C_{1}^{+}(k)=\frac{A_{C}}{\left(\frac{T_{C}}{2}\right)} \propto_{1}^{\mp}-(2 k-1) A_{C}$ Where $\mathrm{k}=1,2,3,4 .$.

\subsubsection{Second step : Find the modified sinusoidal modulation signal equation, $s(k)$.}

To obtain the equation for $\mathrm{S}_{1}(\mathrm{k})$, the middle point for every level of our sample point need to be use . By using basic equation for sinusoidal equation, $y=A \sin (w t)$, equation for $S_{1}(k)$ can be obtain.

For this equation,

$\omega=\frac{2 \pi f_{o}}{f_{c}}$

Where $f_{o}$ is the frequency of modulation signal and $f_{c}$ is the frequency of carrier signal.

So, for $\mathrm{S}_{1}(1)$

$$
\begin{aligned}
& S_{1}(1)=A_{m} \sin \left(\frac{\pi x f_{o}}{f_{c}}\right) \\
& S_{1}(2)=A_{m} \sin \left(\omega+\frac{\pi x f_{o}}{f_{c}}\right) \\
& S_{1}(3)=A_{m} \sin \left(\omega(2)+\frac{\pi x f_{o}}{f_{c}}\right)
\end{aligned}
$$$$
\text { For } \mathrm{S}_{1}(2)
$$$$
\text { For } \mathrm{S}_{1}(3)
$$

General equation for $\mathrm{S}_{1}(\mathrm{k})$

$$
S_{1}(k)=A_{m} \sin \left(\omega(k-1)+\frac{\pi x f_{o}}{f_{c}}\right) \quad \text { Where } \mathrm{k}=1,2,3,4 \ldots .
$$

To find the equation $\mathrm{S}_{2}(\mathrm{k})$, it is similar like $\mathrm{S}_{1}(\mathrm{k})$ but the different is only this signal is shift down from $S_{1}(k)$ signal by the magnitude of Ac. But for $(\pi<t<2 \pi)$ period, $S_{3}(k)$ and $\mathrm{S}_{4}(\mathrm{k})$ will intersect with carrier signal. $\mathrm{S}_{3}(\mathrm{k})$ signal is same with $\mathrm{S}_{1}(\mathrm{k})$ but the different is only this signal is shift up from $\mathrm{S}_{1}(\mathrm{k})$ signal by the magnitude of $A c$ and $\mathrm{S}_{4}(\mathrm{k})$ is different from $\mathrm{S}_{1}(\mathrm{k})$ that is shift up by the magnitude of $2 \mathrm{Ac}$.

So, the general equation for $\mathrm{S}_{2}(\mathrm{k})$

So, the general equation for $\mathrm{S}_{3}(\mathrm{k})$

$$
S_{2}(k)=A_{m} \sin \left(\omega(k-1)+\frac{\pi x f_{o}}{f_{c}}\right)-A_{C}
$$

$$
S_{3}(k)=A_{m} \sin \left(\omega(k-1)+\frac{\pi x f_{o}}{f_{c}}\right)+A_{C}
$$

And the general equation for $\mathrm{S}_{4}(\mathrm{k})$

$$
S_{4}(k)=A_{m} \sin \left(\omega(k-1)+\frac{\pi x f_{o}}{f_{c}}\right)+2 A_{C} \quad \text { Where } k=1,2,3,4 \ldots
$$

\subsubsection{Third step : Find the switching angle equation for Pulse Width Modulation(PWM) switching signal.}

To obtain the switching angle, $\alpha$ equation for PWM signal, the method of intersection between two equation need to be use and the intersection point between equation of carrier signal and equation of modulation signal represent the value of switching angle, $\alpha$.

For $\mathrm{C}_{1}{ }^{-}(\mathrm{k})$ intersection with $\mathrm{S}_{1}(\mathrm{k})$ at $(0<\mathrm{t}<\pi)$,

$$
C_{1}^{-}(k)=S_{1}(k)
$$




$$
\begin{array}{r}
\frac{-A_{C}}{\left(\frac{T_{C}}{2}\right)} \propto_{1}^{-}(k)+(2 k-1) A_{C}=A_{m} \sin \left(\omega(k-1)+\frac{\pi \cdot f_{o}}{f_{c}}\right) \\
A_{C}\left[\frac{-\propto_{1}^{-}(k)}{\left(\frac{T_{C}}{2}\right)}+(2 k-1)\right]=A_{m} \sin \left(\omega(k-1)+\frac{\pi \cdot f_{o}}{f_{c}}\right) \\
\frac{-\propto_{1}^{-}(k)}{\left(\frac{T_{C}}{2}\right)}=-(2 k-1)+\frac{A_{m}}{A_{C}} \sin \left(\omega(k-1)+\frac{\pi \cdot f_{o}}{f_{c}}\right) \propto_{1}^{-}(k) \\
=\frac{T_{C}}{2}\left[(2 k-1)-\frac{A_{m}}{A_{C}} \sin \left(\omega(k-1)+\frac{\pi \cdot f_{o}}{f_{c}}\right)\right]
\end{array}
$$

By using similar method as above, the equation forC ${ }_{1}^{-}(\mathrm{k})$ intersection with $\mathrm{S}_{2}(\mathrm{k})$ at $(0<\mathrm{t}<$ $\pi), \mathrm{C}_{1}^{+}(\mathrm{k})$ intersection with $\mathrm{S}_{1}(\mathrm{k})$ at $(0<\mathrm{t}<\pi), \mathrm{C}_{1}^{+}(\mathrm{k})$ intersection with $\mathrm{S}_{2}(\mathrm{k})$ at $(0<\mathrm{t}<\pi)$, $\mathrm{C}_{1}^{-}(\mathrm{k})$ intersection with $\mathrm{S}_{3}(\mathrm{k})$ at $(\pi<\mathrm{t}<2 \pi), \mathrm{C}_{1}^{-}(\mathrm{k})$ intersection with $\mathrm{S}_{4}(\mathrm{k})$ at $(\pi<\mathrm{t}<2 \pi)$, $\mathrm{C}_{1}^{+}(\mathrm{k})$ intersection with $\mathrm{S}_{3}(\mathrm{k})$ at $(\pi<\mathrm{t}<2 \pi)$, and for $\mathrm{C}_{1}^{+}(\mathrm{k})$ intersection with $\mathrm{S}_{4}(\mathrm{k})$ at $(\pi<\mathrm{t}$ $<2 \pi$ ) can be obtain.Lastly, it can be summerize that the switching angle equation for PWM signal are derived like below:

i. $\quad$ Negative slope $(0<\mathrm{t}<\pi)$

$$
\begin{aligned}
& \propto_{1}^{-}(k)=\frac{T_{C}}{2}\left[(2 k-1)-\frac{A_{m}}{A_{C}} \sin \left(\omega(k-1)+\frac{\pi \cdot f_{o}}{f_{c}}\right)\right] \\
& \propto_{2}^{-}(k)=\frac{T_{C}}{2}\left[(2 k)-\frac{A_{m}}{A_{C}} \sin \left(\omega(k-1)+\frac{\pi \cdot f_{o}}{f_{c}}\right)\right]
\end{aligned}
$$

ii. Positive slope $(0<\mathrm{t}<\pi)$

$$
\begin{aligned}
& \propto_{1}^{+}(k)=\frac{T_{C}}{2}\left[(2 k-1)+\frac{A_{m}}{A_{C}} \sin \left(\omega(k-1)+\frac{\pi \cdot f_{o}}{f_{c}}\right)\right] \\
& \propto_{2}^{+}(k)=\frac{T_{C}}{2}\left[(2 k-2)+\frac{A_{m}}{A_{C}} \sin \left(\omega(k-1)+\frac{\pi \cdot f_{o}}{f_{c}}\right)\right]
\end{aligned}
$$

iii. Negative slope $(\pi<\mathrm{t}<2 \pi)$

$$
\begin{aligned}
& \propto_{1}^{-}(k)=\frac{T_{C}}{2}\left[(2 k-2)-\frac{A_{m}}{A_{C}} \sin \left(\omega(k-1)+\frac{\pi \cdot f_{o}}{f_{c}}\right)\right] \\
& \propto_{2}^{-}(k)=\frac{T_{C}}{2}\left[(2 k-3)-\frac{A_{m}}{A_{C}} \sin \left(\omega(k-1)+\frac{\pi \cdot f_{o}}{f_{c}}\right)\right]
\end{aligned}
$$

iv. Positive slope $(\pi<\mathrm{t}<2 \pi)$

$$
\begin{array}{r}
\propto_{1}^{+}(k)=\frac{T_{C}}{2}\left[(2 k)+\frac{A_{m}}{A_{C}} \sin \left(\omega(k-1)+\frac{\pi \cdot f_{o}}{f_{c}}\right)\right] \\
\propto_{2}^{+}(k)=\frac{T_{C}}{2}\left[(2 k+1)+\frac{A_{m}}{A_{C}} \sin \left(\omega(k-1)+\frac{\pi \cdot f_{o}}{f_{c}}\right)\right] \text { Where } \mathrm{k}=1,2,3,4 . .
\end{array}
$$




\section{Results}

After the equation of switching angle are carried out, verification need to be done by comparing the result that come from the derived equation and the result that come out from simulation. If the errors between both results are very small or equal to zero, than the derived equation is verified and accepted.

\subsection{Comparison between Matlab simulation results and result from derive equation.}

Table 1 and Table 2 below show that the different between simulation result and result from derive equation. It shows that percentage error between both result are equal to zero. It also shows that the equation are verified and accepted.

Table 1. Comparison Result for $(0<\mathrm{t}<\pi)$

\begin{tabular}{|c|c|c|c|}
\hline & Simulation (radian) & Derived Equation(radian) & \% ERROR \\
\hline$\alpha 1(1)$ & 0.1202 & 0.1202 & 0.000 \\
\hline$\alpha 1(1)$ & 0.1939 & 0.1939 & 0.000 \\
\hline$\alpha 1(2)$ & 0.3643 & 0.3643 & 0.000 \\
\hline$\alpha 1(2)$ & 0.5782 & 0.5782 & 0.000 \\
\hline$\alpha 2(3)$ & 0.7759 & 0.7759 & 0.000 \\
\hline$\alpha 2(3)$ & 0.7949 & 0.7949 & 0.000 \\
\hline$\alpha 2(4)$ & 1.0467 & 1.0467 & 0.000 \\
\hline$\alpha 2(4)$ & 1.1524 & 1.1524 & 0.000 \\
\hline$\alpha 2(5)$ & 1.3381 & 1.3381 & 0.000 \\
\hline$\alpha 2(5)$ & 1.4894 & 1.4894 & 0.000 \\
\hline$\alpha 2(6)$ & 1.6522 & 1.6522 & 0.000 \\
\hline$\alpha 2(6)$ & 1.8035 & 1.8035 & 0.000 \\
\hline$\alpha 2(7)$ & 1.9892 & 1.9892 & 0.000 \\
\hline$\alpha 2(7)$ & 2.0949 & 2.0949 & 0.000 \\
\hline$\alpha 2(8)$ & 2.3467 & 2.3467 & 0.000 \\
\hline$\alpha 2(8)$ & 2.3657 & 2.3657 & 0.000 \\
\hline$\alpha 1(9)$ & 2.5634 & 2.5634 & 0.000 \\
\hline$\alpha 1(9)$ & 2.7773 & 2.7773 & 0.000 \\
\hline$\alpha 1(10)$ & 2.9476 & 2.9477 & 0.000 \\
\hline$\alpha 1(10)$ & 3.0214 & 3.0214 & 0.000 \\
\hline
\end{tabular}


Table 2. Comparison result $(\pi<\mathrm{t}<2 \pi)$

\begin{tabular}{|c|c|c|c|}
\hline & Simulation (radian) & Derived Equation(radian) & \% ERROR \\
\hline$\alpha 1(11)$ & 3.1784 & 3.1785 & 0.000 \\
\hline$\alpha 1(11)$ & 3.4189 & 3.4189 & 0.000 \\
\hline$\alpha 1(12)$ & 3.5627 & 3.5627 & 0.000 \\
\hline$\alpha 1(12)$ & 3.6630 & 3.6629 & 0.000 \\
\hline$\alpha 2(13)$ & 3.7794 & 3.7794 & 0.000 \\
\hline$\alpha 2(13)$ & 4.0746 & 4.0745 & 0.000 \\
\hline$\alpha 2(14)$ & 4.1369 & 4.1369 & 0.000 \\
\hline$\alpha 2(14)$ & 4.3454 & 4.3454 & 0.000 \\
\hline$\alpha 2(15)$ & 4.4739 & 4.4739 & 0.000 \\
\hline$\alpha 2(15)$ & 4.6368 & 4.6368 & 0.000 \\
\hline$\alpha 2(16)$ & 4.7880 & 4.7880 & 0.000 \\
\hline$\alpha 2(16)$ & 4.9509 & 4.9509 & 0.000 \\
\hline$\alpha 2(17)$ & 5.0794 & 5.0794 & 0.000 \\
\hline$\alpha 2(17)$ & 5.2878 & 5.2878 & 0.000 \\
\hline$\alpha 2(18)$ & 5.3502 & 5.3502 & 0.000 \\
\hline$\alpha 2(18)$ & 5.6453 & 5.6453 & 0.000 \\
\hline$\alpha 1(19)$ & 5.7619 & 5.7618 & 0.000 \\
\hline$\alpha 1(19)$ & 5.8620 & 5.8621 & 0.000 \\
\hline$\alpha 1(20)$ & 6.0059 & 6.0059 & 0.000 \\
\hline$\alpha 1(20)$ & 6.2463 & 6.2463 & 0.000 \\
\hline
\end{tabular}

\section{Discussion}

After result has been verified, there show that simulation result is identical to the result that obtains from the derived equation. Based on Table 1 and Table 2, It shows the PWM output signal that obtain from derived equation and matlab simulation. It is exactly same and zero percentage error. This derived equation will make more easier for us because it can be use in digital purpose. It is well know that the digital technique had many advantages compared to analog technique.

\section{Conclusion}

The objectives for this project are to derive a new mathematical equation that defines the switching instants of sinusoidal pulse width modulation (SPWM) for multilevel voltage source inverter. This derive equation also was verified by comparing with MATLAB simulation. From the comparison, both results that come from simulation and from derived equation is exactly same. It gives almost zero percentage error. It means that the derived equation are verified and accepted.

\section{References}

1. J. Aziz, Z. Salam, "An alternative PWM scheme for multilevel voltage source inverter. Power Engineering Conference, 2003. PECon 2003. Proceedings. National. 83-87, (2003)

2. J.A. Aziz, Z. Salam, A PWM strategy for the modular structured multilevel inverter suitable for digital implementation. Power Electronics Congress, 2002. Technical Proceedings. CIEP 2002. VIII IEEE International. 160-164, (2002) 
3. S. Zainal, J. Aziz, S.S. Ahmed, Single carrier PWM scheme for cascaded multilevel voltage source inverter. Power Electronics and Drive Systems, 2003. PEDS 2003. The Fifth International Conference. IEEE. 1, 406-410, (2003)

4. V.K. Chinnaiyan, J. Jerome, J. Karpagam, T. Suresh, Control techniques for multilevel voltage source inverters. 2007 International Power Engineering Conference (IPEC 2007). IEEE. 1023-1028, (2007)

5. X. Xu, Y. Zou, K. Ding, F. Liu, Cascade multilevel inverter with phase-shift SPWM and its application in STATCOM. Industrial Electronics Society, 2004. IECON 2004. 30th Annual Conference of IEEE. 2, 1139-1143, (2004) 